\title{
Self-Compassion as a Predictor of Self-Care: A Study of Social Work Clinicians
}

\author{
J. Jay Miller ${ }^{1}$ Jacquelyn Lee ${ }^{2} \cdot$ Chunling Niu ${ }^{1} \cdot$ Erlene Grise-Owens $^{3} \cdot$ Molly Bode $^{4}$
}

Published online: 29 May 2019

(c) Springer Science+Business Media, LLC, part of Springer Nature 2019

\begin{abstract}
Despite the promise of self-care in dealing with employee challenges, there is nominal research related to this topic, in general, and among the clinical social work workforce, specifically. This exploratory study examines self-compassion, selfcare, and the predictive relationship between the two among a sample $(\mathrm{N}=831)$ of clinical social workers practicing in one southeastern state. In so doing, this paper uniquely addresses several limitations in the current literature. Findings suggest that social work clinicians in this sample engaged in moderate amounts of self-compassion and self-care, respectively. As well, self-compassion proved to be a unique and significant predictor of both personal and professional self-care, respectively. Findings from this study suggest the need to more deftly support clinicians in engaging in self-compassion and self-care, which includes ongoing training, education, and skill development.
\end{abstract}

Keywords Self-compassion $\cdot$ Social workers $\cdot$ Self-care $\cdot$ Clinical $\cdot$ Clinicians

There is growing attention to the need for deft self-care practices among mental health professionals, in general, and among clinical social workers, specifically. This increasing awareness is predicated on contemporary practice challenges that pose challenges for those proffering mental/behavioral health services. A plethora of authors have postulated that social work practitioners are at increased risk for burnout, vicarious trauma, and other problematic circumstances (Dunkley and Whelan 2006; National Association of Social Workers 2008; Lee and Miller 2013; Miller et al. 2017).

Despite the promise of self-care in dealing with these problematic circumstances, and thus potentially improving clinical services proffered to clients, there is nominal research related to this topic, in general (National Association of Social Workers [NASW] 2008; Lee and Miller 2013;

J. Jay Miller

jaymiller45@hotmail.com

1 Self-Care Lab, College of Social Work, University of Kentucky, Lexington, USA

2 University of North Carolina - Wilmington, Wilmington, USA

3 The Wellness Group, ETC, Los Angeles, USA

4 College of Social Work, University of Kentucky, Lexington, USA
Cox and Steiner 2013; Bloomquist et al. 2015). Of particular paucity are studies that examine factors that contribute to this employment group engaging in self-care. This paper seeks to contribute to addressing these limitations.

This exploratory study examines self-compassion, selfcare, and the predictive relationship between the two among a sample $(\mathrm{N}=831)$ of social work clinicians in one southeastern state. Based on a thorough literature review of relevant databases (e.g., PubMed, Ebscohost, etc.), this is the first such study to examine these areas. After providing some relevant background information, this paper will review literature informing this study, explicate results, and discuss implications for clinical training, practice, and research.

\section{Background}

\section{Terminology}

Terminology associated with self-care and wellness, particularly in a professional context, are frequently muddled or misunderstood (Cleantis 2017). Divergent terminology and ambiguous practices contribute to this lack of understanding. Thus, the following paragraphs will briefly define terms relevant to understanding this study. 


\section{Defining Self-Compassion}

A number of works examined the concept of self-compassion. Neff (2003a), who is the leading expert associated with the topic, defined self-compassion as creating and subsequently nurturing a relationship with the self that allows a sense of caring and warmth. Neff explicated that self-compassion is comprised of three characteristics: kindness, a sense of common humanity, and mindfulness. Further, Neff described self-compassion as a way of relating to self as we would relate positively to others: restraining judgment, seeking good, accepting or tolerating flaws, and balancing strengths with challenges.

To fully grasp the construct of self-compassion, it is pertinent to draw a distinction between it, and compassion (Neff and Germer 2017). Merriam-Webster (2017) defined compassion as "sympathetic consciousness of others' distress together with a desire to alleviate it." Neff and Germer (2017) further explained that compassion fosters a "willingness to extend that understanding to others when they fail or make mistakes" (p. 1). Compassion, then, is an ability to connect interpersonally, whereas self-compassion is the ability to connect intrapersonally. Neff and Germer (2013) described self-compassion as "compassion directed inward" (p. 1).

\section{Defining Self-Care}

Likewise, defining self-care can be somewhat challenging. Similar to other wellness terminology, the challenges are related to divergent uses and prevailing misnomers, myths, and misunderstandings (e.g., Smullens 2015; Bush 2015; Lee and Miller 2013; Cleantis 2017). These difficulties notwithstanding, several authors have proffered definitions for self-care. For example, Dorociak et al. (2017) defined self-care as a "multidimensional, multifaceted process of purposeful engagement in strategies that promote healthy functioning and enhance well-being" (p. 326). These domains may include social, spiritual, psychological, physical, and professional aspects. NASW (2008) and Lee and Miller (2013) demarcated two explicit areas of selfcare: professional and personal. Lee and Miller explained that personal self-care includes engaging in practices that promote wellbeing of the self, whilst professional selfcare includes attention to practices that promote wholistic health of the professional self. These authors explained that these two areas of self-care converge to "empower practitioners to exert agency over their holistic health and well-being," and ultimately a means by which the culture of the profession can be shifted (Lee and Miller 2013, p. 99).

\section{Challenges Facing Clinical Social Workers}

The contemporaneous challenges facing social work clinicians are multifarious and well-documented. More broadly, over the past decade, social work practitioners have faced a host of organizational challenges such growing case-load sizes and increasingly complex client needs (Arrington 2008; Cox and Steiner 2013; Whitaker et al. 2006). Moreover, social service entities are often inordinately impacted by sensitive political environments and resource/funding restrictions (Cox and Steiner 2013).

Beyond broad contextual concerns, clinical social workers are at risk for experiencing a host of problematic consequences. For example, due to the nature of their work, clinical social workers are regularly exposed to the traumatic experiences of clients. This secondary exposure, termed secondary traumatic stress, is characterized by symptomology parallel to post-traumatic stress, and in severe cases, may meet the diagnostic criteria for post-traumatic stress disorder (Bride and Figley 2009). Christopher and Maris (2010) asserted that practitioners who provide counseling services are at increased threat for burnout, compassion fatigue, and vicarious traumatization. Others have made similar assertions (Berthold and Fischman 2014; Bourassa 2009; Ben-Porat and Itzhaky 2009; Kintzle et al. 2013; Ting et al. 2005). Issues related to transference and countertransference can compound these challenges.

\section{Importance of Self-Compassion and Self-Care}

Few would debate the importance of self-compassion and self-care, respectively and perhaps in combination, for clinicians. In fact, evidence indicates that healthy selfcompassion and self-care practices may assuage many of the problematic employment circumstances previously detailed in this narrative. Whilst not many studies have specifically examined the impact of self-compassion and self-care practices on helping professionals, significant general research has particular pertinence.

For instance, self-compassion has been linked to improved mental health outcomes (Neff 2003a) and is negatively correlated with psychopathology (Yarnell et al. 2015). Durkin et al. (2016) concluded that self-compassion was significantly associated with a positive sense of personal wellbeing. Raes et al. (2011) affirmed this notion and further asserted that self-compassion may assist individuals in processing negative experiences. Others have suggested that self-compassion can prompt healthy behavior (Sirois et al. 2015), improved relationship building (Gerber et al. 2015), and compassion towards others (Neff and 
Beretvas 2013). Ferguson et al. (2014) found that selfcompassion acts as a powerful force that promotes action and growth, thus increasing initiative and perseverance in helping to reach full potential.

Neff (2011) reported on research that suggests that caregivers trained in self-compassion are less likely to experience compassion fatigue. Actually, they report more "compassion satisfaction"-i.e., feeling energized and experiencing meaning in their work (p. 192). Neff (2011) surmised that caregivers with self-compassion are more likely to engage in "concrete acts of self-care," such as taking time off, getting adequate sleep, and having a healthy diet (p. 193).

Like self-compassion, there are indications that self-care can be an antidote to some of the employment challenges plaguing social work clinicians. For example, among a sample of child welfare practitioners, Salloum et al. (2015) found that self-care is linked to lower levels of professional burnout, as well as higher levels of compassion satisfaction related to their jobs. Others have also affirmed that self-care may assuage burnout (Cohen and Gagin 2005). Sanso et al. (2015) suggested that self-care may be positively related to professional efficacy and Asuero et al. (2014) asserted that self-care may be related to increased perceptions of professionalism.

The parallels between self-compassion and self-care seem intuitively apparent. The research on these topics, separately, seem to point to a complementary or interactive relationship. However, this relationship is relatively unexamined and, thus, largely untapped for potential applications to practice.

The implications of the literature on these topics (i.e., self-care, and self-compassion), as treated separately, are clear. The challenges facing clinicians are diverse and complex. As such, practitioners, policy makers, and researchers must examine concepts with the potential to allay these challenges. Growing research indicates the impact and potential of self-compassion and self-care, respectively. However, few, if any, have examined the relationship between these two constructs-particularly among social work clinicians. This study seeks to address this dearth in the current literature, which will inform future studies.

\section{Research Foci}

The primary focus of this exploratory study was to examine self-compassion, self-care, and the interaction between the two, among a sample of social work clinicians. In so doing, this paper addresses a unique gap in the current research literature. This research effort was guided by three distinct research queries:

1. How do social work clinicians fare in terms of self-compassion and self-care, respectively?
2. What is the relationship(s) between demographic and professional characteristics and self-compassion and self-care, respectively?

3. Is self-compassion a significant predictor of professional and personal self-care, respectively?

\section{Methods and Materials}

\section{Sampling and Protocol}

This paper is part of a larger study that examined wellness and self-care among social workers. To collect data relevant to this narrative, participants for this study were recruited via a non-random convenience sampling procedure. Participants self-selected into the study by responding to an online survey invitation. The invitation was sent out during Winter 2017. Potential participants were asked to forward the survey invitation to other kinship caregivers. Additionally, the survey invitation was posted to various social media platforms. Thus, calculating a response rate is not possible.

Each participant received the approved informed consent document upon entering the online survey invitation. A waiver of documentation for the informed consent was granted and requested by a University Institutional Review Board (IRB). Participants were asked to read the consent before entering the survey. All participants in this study identified as a clinical social worker, currently holding a clinical social work license.

The survey was administered and managed via an online survey management system. All data were collected during the first quarter of 2018. Upon completion of the survey, participants were offered a chance to enter a $\$ 500$ incentive drawing for their participation. The incentive survey was disconnected for the primary survey via a separate link. As such, participants responses could not be traced back to them. To reiterate, this protocol was approved by a University IRB.

\section{Instrumentation}

The measure used for this study was divided into three overarching parts. First, participants responded to a number of demographic/general information items. Personal characteristics such as gender, race/ethnicity, and sexual orientation and relationship status were measured via dichotomous or ordinal items. Education was measured categorically in which participants selected their highest level of education. Health status was measured by a 5-point ordinal scale asking participants to rate their overall health status from excellent to poor. Financial situation was measured using a categorical item in which participants were asked to select the response that best described 
their financial status. Selection categories were as follows: "I cannot make ends meet," "I have just enough money to make ends meet," "I have enough money, with a little left over," or "I always have enough money left over." Lastly, multiple categorical items measured participants' employer and work environment features.

Second, to measure self-care, researchers utilized the Self-Care Practices Scale (SCPS). SCPS is 38-item instrument designed to assess the frequency in which participants take part in professional and personal self-care, respectively. The SCPS uses a likert-type scale anchored at 0 (indicating "never") to 4 (indicating "very often") and produces a personal self-care score ranging from 0 to 64 and a professional self-care score ranging from 0 to 88 . Higher scores indicate that the respondent more frequently engages in selfcare practices. For this study, Cronbach's alphas for the personal and professional self-care scales were 0.82 and 0.77 , respectively.

Third, researchers utilized the Self-Compassion Scale (SCS; Neff 2003a, b), which is a 26-item self-report measure designed to assess the frequency of compassionate responsiveness to the self. In addition to a summative score, the SCS generates scores for six subscales that represent both the three conceptual aspects of self-compassion and their opposing actions, respectively: Mindfulness vs Over-identification, Common Humanity vs Isolation, and Self-kindness versus Self-judgement (Neff 2003a, b). Items identify various responses toward the self in challenging moments (e.g., I'm disapproving and judgmental about my own flaws and inadequacies; I try to be loving towards myself when I'm feeling emotional pain), and responses are invited to endorse how often they engage in each action using a 5-point Likert-type scale anchored from 1 (almost never) to 5 (almost always). Research suggests the SCS demonstrates good test-retest reliability, internal consistency across subscales, and convergent, discriminate, and cross-cultural validity (Neff 2003b; Neff et al. 2008; Van Dam et al. 2011). In this study, Cronbach's alpha was 0.92 for the overall self-compassion scale and ranged from 0.74 to 0.85 for the subscales.

\section{Results}

\section{Participants}

A total of 831 clinical social workers participated in this study. The typical participant identified as Female, White/ Caucasian, and aged $41.46(\mathrm{SD}=11.57)$ years. On average, participants had been practicing social work for 13.46 $(\mathrm{SD}=9.88)$ years and worked $40.69(\mathrm{SD}=9.96)$ hours per week. Additional personal and professional data are included in Table 1.
Table 1 Description of participants

\begin{tabular}{|c|c|}
\hline Social workers' characteristics & $N(\%)$ \\
\hline \multicolumn{2}{|l|}{ Gender } \\
\hline Male & $92(11.1)$ \\
\hline Female & $731(88.2)$ \\
\hline Other & $6(0.8)$ \\
\hline \multicolumn{2}{|l|}{ Ethnicity } \\
\hline White & $731(88.3)$ \\
\hline Black & $72(8.7)$ \\
\hline Other (Biracial/Multiracial, Asian, \& Hispanic) & $25(3.0)$ \\
\hline \multicolumn{2}{|l|}{ Marital status } \\
\hline Married & $538(64.9)$ \\
\hline Never married & $149(18.0)$ \\
\hline Partnered & $46(5.5)$ \\
\hline Divorced & $73(8.8)$ \\
\hline Other (widowed and separated) & $23(2.8)$ \\
\hline \multicolumn{2}{|l|}{ Gross annual household income } \\
\hline Less than $\$ 29,999$ & $28(3.4)$ \\
\hline$\$ 30,000-\$ 59,999$ & $310(37.6)$ \\
\hline$\$ 60,000-\$ 99,999$ & $270(32.8)$ \\
\hline$\$ 100,000-\$ 199,999$ & $199(24.2)$ \\
\hline$\$ 200,000$ or more & $16(1.9)$ \\
\hline \multicolumn{2}{|l|}{ Current financial status } \\
\hline I cannot make ends meet & $38(4.6)$ \\
\hline I have just enough money to make ends meet & $233(28.1)$ \\
\hline I have enough money, with a little left over & 408(49.3) \\
\hline I always have money left over & $149(18.0)$ \\
\hline \multicolumn{2}{|l|}{ Education } \\
\hline Bachelors & $57(6.9)$ \\
\hline Masters & $748(90.1)$ \\
\hline $\begin{array}{l}\text { Others (high school, associates, first professional, and } \\
\text { doctorate) }\end{array}$ & $25(3.0)$ \\
\hline \multicolumn{2}{|l|}{ Profit or non-profit work settings } \\
\hline For profit & $264(32.7)$ \\
\hline Non-profit & $541(67.0)$ \\
\hline \multicolumn{2}{|l|}{ Current member of professional organization(s) } \\
\hline Yes & $282(34.0)$ \\
\hline No & $548(66.0)$ \\
\hline \multicolumn{2}{|l|}{ Supervise other social workers } \\
\hline Yes & $185(22.3)$ \\
\hline No & $646(77.7)$ \\
\hline \multicolumn{2}{|l|}{ Perceived health status } \\
\hline Excellent & $116(14.0)$ \\
\hline Very good & $365(43.9)$ \\
\hline Good & $275(33.1)$ \\
\hline Other (fair and poor) & $75(9.0)$ \\
\hline
\end{tabular}

\section{Self-Care and Self-Compassion}

Table 2 presents descriptive statistics (including means and standard deviation scores) for outcome measures pertaining 
Table 2 Self-care and selfcompassion scores

\begin{tabular}{llllllll}
\hline Dependent variables & $M$ & SD & Max & Min & Skewness & Kurtosis & $N$ \\
\hline Personal self-care & 59.71 & 8.53 & 80 & 16 & -.28 & .83 & 831 \\
Professional self-care & 82.52 & 10.17 & 110 & 22 & -.27 & 1.63 & 819 \\
Self-compassion & 3.34 & 0.69 & 5 & 1 & -.03 & .05 & 794 \\
\hline
\end{tabular}

to both Self-Compassion (the overall score combining 6 subscales: Self-Kindness, Self-Judgment, Common Humanity, Isolation, Mindfulness, and Over-Identification) and SelfCare (including Personal Self-Care and Professional SelfCare, respectively).

As indicated, skewness and kurtosis values appeared within the acceptable range, suggesting relatively normal distribution of the data. In addition, all the study variables were negatively skewed, suggesting that most respondents tended to rate on the relatively higher end of the scales. These issues require caution in interpretation of data analysis results.

Because individual differences in social workers' demographic and professional backgrounds may contribute to part of the differences in their ratings on self-compassion and self-care scales, correlations and group differences were examined to reveal the interaction pattern between the background factors and the study variables.

Due to statistical considerations, the mean comparison procedures were intentionally narrowed to the selected levels under certain categorical variables. For instance, there were only $3 \%$ of the respondents in the sample who reported they had received academic degrees other than Bachelor's or Master's degrees. To increase the accuracy of the statistical results, the researchers chose to exclude these "outliers" in the dataset from the statistical analyses. Group difference analyses among categorical variables are included in Table 3 .

Table 3 suggests that members of professional organization(s) rated significantly higher than non-members on Self-Compassion [ $M$ diff $=.14 ; t(791)=2.58, p<.05]$, Personal Self-Care $[M$ diff $=1.93 ; t(828)=3.10, p<.01]$, and Professional Self-Care $[M$ diff $=2.61 ; t(816)=3.50$, $p<.01]$; and social worker supervisors rated significantly higher than non-supervisors on Self-Compassion [M diff $=.12 ; t(792)=1.99, p<.05]$, Personal Self-Care $[M$ diff $=1.51 ; t(829)=2.13, p<.05]$, and Professional SelfCare $[M$ diff $=1.80 ; t(817)=2.13, p<.05]$. Moreover, regarding marital status, married respondents gave higher ratings than those who were never married on Personal Self-Care $[M$ diff $=1.28 ; t(829)=2.07, p<.05]$. Last, the participants' current financial situation led to significant cross-group mean differences on Self-Compassion, $F$ (3, $790)=10.31, p<.01$, where the respondents who reported "I cannot make ends meet" $(M=2.95, S D=0.90)$ and "I have just enough money to make ends meet" $(M=3.18, S D=0.64)$ rated significantly lower than those who claimed "I have enough money with a little left over" $(M=3.39, S D=0.66)$ or "I always have money left over" $(M=3.54, S D=0.71)$; Personal Self-Care, $F(3,827)=25.12, p<.01$, where the respondents who reported "I cannot make ends meet" $(M=54.21, S D=10.58)$ rated significantly lower than those who claimed "I have enough money with a little left over" $(M=60.08, S D=7.89)$ or "I always have money left over" $(M=64.27, S D=8.41)$; and Professional Self-Care, $F$ (3, $815)=9.30, p<.01$, where the respondents who reported "I always have money left over" $(M=86.10, S D=10.49)$ rated significantly higher than those who claimed "I cannot make ends meet" $(M=77.03, S D=14.68)$, "I have just enough money to make ends meet" $(M=80.70, S D=9.56)$, or "I have enough money with a little left over" $(M=82.76$, $S D=9.47)$.

As indicated in Table 4, Age correlated significantly with all study variables $(p s<.01)$ : self-compassion $(r=.253)$; personal self-care $(r=.241)$; and professional self-care $(r=.250)$. Similarly, Perceived Health Status (ranging from
Table 3 Interaction between categorical and outcome variables

\begin{tabular}{|c|c|c|c|c|c|c|c|c|c|}
\hline \multirow[t]{3}{*}{ Demographics } & \multicolumn{9}{|c|}{ Outcomes } \\
\hline & \multicolumn{3}{|c|}{ Personal self-care } & \multicolumn{3}{|c|}{ Professional self-care } & \multicolumn{3}{|c|}{ Self-compassion } \\
\hline & $t / F$ & $d f$ & $d / \eta^{2}$ & $t / F$ & $d f$ & $d / \eta^{2}$ & $t / F$ & $d f$ & $d / \eta^{2}$ \\
\hline Current relationship status ${ }^{\mathrm{a}}$ & $2.07 *$ & 829 & 0.14 & 1.85 & 817 & 0.13 & 1.90 & 792 & 0.14 \\
\hline Current financial situation & $25.12 * *$ & 3,827 & 0.10 & $9.30 * *$ & 3,815 & 0.05 & $10.31 * *$ & 3,790 & 0.05 \\
\hline Supervise others & $2.13^{*}$ & 829 & 0.15 & $2.13 *$ & 817 & 0.15 & $1.99 *$ & 792 & 0.14 \\
\hline $\begin{array}{l}\text { Current member of profes- } \\
\text { sional organization(s) }\end{array}$ & $3.10 * *$ & 828 & 0.22 & $3.50 * *$ & 816 & 0.25 & $2.58^{*}$ & 791 & 0.18 \\
\hline
\end{tabular}

$* p<0.05, * * p<0.01$

${ }^{\mathrm{a}}$ Mean comparison between the two levels: married versus not married 
Table 4 Pearson correlation matrix among self-care scores, self-compassion scores, and selected personal/professional characteristics

\begin{tabular}{lllll}
\hline Outcomes & Age & $\begin{array}{l}\text { Perceived } \\
\text { health } \\
\text { status }\end{array}$ & $\begin{array}{l}\text { Hours for } \\
\text { work per } \\
\text { week }\end{array}$ & $\begin{array}{l}\text { Years } \\
\text { in SW } \\
\text { practice }\end{array}$ \\
\hline Self-compassion & $.253^{* *}$ & $-.270^{* *}$ & -.053 & $.269^{* *}$ \\
Personal self-care & $.241^{* *}$ & $-.434^{* *}$ & $-.112^{* *}$ & $.255^{* *}$ \\
Professional self-care & $.250^{* *}$ & $-.251^{* *}$ & $-.164^{* *}$ & $.235^{* *}$ \\
\hline
\end{tabular}

$* p<0.05, * * p<0.01$

"Poor" to "Excellent") ( $p s<.01)$ and Years in SW Practice ( $p$ s $<.01)$ also significantly related to all the above listed three study variables. Hours for Work per Week were found only significantly associated with the two self-care variables ( $p$ s <.01): personal self-care $(r=-.112)$; and professional self-care $(r=-.164)$.

These above-mentioned background factors that implied significant effects on the study variables were controlled for in examining the unique predictive relationships between self-compassion and self-care.

\section{Regression Analysis}

Since several significant correlations were detected between participants' background factors and self-compassion scores as reported previously, collinearity statistics were examined for any multi-collinearity concerns prior to a hierarchical multiple regression analysis. The diagnose showed collinearity statistics (i.e., Tolerance and VIF) were all within accepted limits, the assumption of multi-collinearity was deemed to have been met (Coakes 2005; Hair et al. 1998).

A two stage hierarchical multiple regression was then conducted with Personal and Professional Self-Care Practice as the dependent variables. Selected Personal and Professional Demographics (i.e., Age, Marital Status, Hours for Work per Week, Years in Practice, Member of Professional Organization, Current Financial Situation, and Perceived Health) were entered at stage one of the regression to control for significant demographic differences in individuals. The Self-Compassion variable was entered at stage two.

Table 5 presents the regression statistics. The results revealed that at Stage one, Age, Perceived Health, Hours for Work per Week, and the specific Current Financial Situation conditions ("I always have money left over."; "I have just enough money to make ends meet."; and "I have enough money with a little left over.") contributed significantly to the regression model related to Personal Self-Care, and accounted for $27.5 \%$ of the variation in Personal Self-Care $[F(9,660)=27.42, p<.001]$. Adding the Self-Compassion variables to the regression model explained an additional $14.2 \%$ of variation in Personal Self-Care. The change in $R^{2}$ was significant for Personal Self-Care $[F(1,650)=157.89$, $p<.001]$.

While in the regression model concerning Professional Self-Care, the significant predictors at Stage one included Age, Perceived Health, Hours for Work per Week, Member of Professional Organization(s), and the specific Current Financial Situation condition (("I always have money left over." and "I have just enough money to make ends meet."), which accounted for $15.1 \%$ of the total variation in Professional Self-Care $[F(9,660)=12.86, p<.001]$. Adding the Self-Compassion variables to the regression model explained an additional $14.3 \%$ of variation in Professional Self-Care. The change in $R^{2}$ was significant for Professional Self-Care $[F(1,650)=132.14, p<.001]$.

When all eight independent variables were included in stage two of the regression models, Self-Compassion (uniquely explained $19.5 \%$ of the variation) became the most significant predictors of Personal Self-Care, followed by Perceived Health (accounted for $10.2 \%$ of the variation), and the specific Current Financial Status condition ("I have just enough money to make ends meet.") (contributed to $2.6 \%$ of the variation). While for Professional Self-Care, SelfCompassion (uniquely accounted for $16.9 \%$ of the variation) also emerged as the strongest predictor, followed by Hours for Work per Week (contributed to $2 \%$ of the variation) and Perceived Health (uniquely explained $1.1 \%$ of the variation).

Together the eight independent variables accounted for $41.7 \%$ of the variance in Personal Self-Care and $29.4 \%$ in Professional Self-Care.

\section{Discussion}

The primary aim of this exploratory study was to examine self-compassion, self-care, and the interaction between the two, among a sample of clinical social workers in one southeastern state. Specifically, this study examined the predictive relationship of self-compassion on professional and personal self-care practices, respectively. By addressing this area, this paper uniquely contributes to addressing a dearth in the research literature related to social work clinicians. The following paragraphs briefly outline salient discussion points derived from the afore-presented results. For clarity and ease of reading, this section is centered around explicitly addressing the previously posited research questions.

\section{Self-Care and Self-Compassion Scores}

Overall, findings from this study suggest that clinicians in this sample only engaged in moderate levels of self-compassion and self-care. Participants' mean self-compassion was 3.34 ( $\mathrm{SD}=0.69)$. This score indicates that participants were only sometimes self-compassionate. This finding is similar 
Table 5 Summary of hierarchical regression analysis

\begin{tabular}{|c|c|c|c|c|c|c|}
\hline Predictors & $\beta$ & $\mathrm{t}$ & $s r^{2}$ & $F$ & $R^{2}$ & $\Delta R^{2}$ \\
\hline Step 1 & & & & $27.42 * *(12.86 * *)$ & $.275(.151)$ & $.275(.151)$ \\
\hline Age & $.16^{\mathrm{a}}\left(.20^{\mathrm{b}}\right)$ & $3.12 * *\left(3.58^{* *}\right)$ & $.015(.019)$ & & & \\
\hline Marital status & $.01(-.01)$ & $.03(-.02)$ & $<.001(<.001)$ & & & \\
\hline Hours for work per week & $-.07(-.13)$ & $-2.09 *(-3.44 * *)$ & $.007(.018)$ & & & \\
\hline Years in practice & $.06(.01)$ & $1.16(.15)$ & $.002(<.001)$ & & & \\
\hline Member of professional organization(s) & $-.05(-.09)$ & $-1.49\left(-2.57^{*}\right)$ & $.003(.010)$ & & & \\
\hline \multicolumn{7}{|l|}{ Current financial situation } \\
\hline I always have money left over & Reference & & & & & \\
\hline I cannot make ends meet & $-.11(-.10)$ & $-2.74 * *(-2.42 *)$ & $.011(.009)$ & & & \\
\hline I have enough money to make ends meet & $-.22(-.11)$ & $-4.55^{* *}\left(-2.15^{*}\right)$ & $.031(.007)$ & & & \\
\hline I have enough money with a little left over & $-.13(-.09)$ & $-2.69 * *(-1.76)$ & $.011(.005)$ & & & \\
\hline Perceived health status & $-.38(-.20)$ & $-10.88^{* *}\left(-5.30^{* *}\right)$ & $.153(.041)$ & & & \\
\hline Step 2 & & & & $46.42 * *(27.12 * *)$ & $.417(.294)$ & $.142(.143)$ \\
\hline Age & $.09(.13)$ & $1.97 *(2.54 *)$ & $.006(.010)$ & & & \\
\hline Marital status & $-.01(-.01)$ & $-.39(-.42)$ & $<.001(<.001)$ & & & \\
\hline Hours for work per week & $-.07(-.12)$ & $-2.17 *(-3.62 * *)$ & $.007(.020)$ & & & \\
\hline Years in practice & $.03(-.02)$ & $.69(-.39)$ & $.001(<.001)$ & & & \\
\hline Member of professional organization(s) & $-.04(-.08)$ & $-1.24\left(-2.44^{*}\right)$ & $.002(.009)$ & & & \\
\hline \multicolumn{7}{|l|}{ Current financial situation } \\
\hline I always have money left over & Reference & & & & & \\
\hline I cannot make ends meet & $-.08(-.07)$ & $-2.25 *(-1.92)$ & $.008(.006)$ & & & \\
\hline I have enough money to make ends meet & $-.18(-.07)$ & $-4.13 * *(-1.50)$ & $.026(.003)$ & & & \\
\hline I have enough money with a little left over & $-.12(-.09)$ & $-2.89 * *(-1.83)$ & $.013(.005)$ & & & \\
\hline Perceived health status & $-.28(-.10)$ & $-8.59 * *(-2.74 * *)$ & $.102(.011)$ & & & \\
\hline Self-compassion & $.41(.41)$ & $12.57 * *\left(11.50^{* *}\right)$ & $.195(.169)$ & & & \\
\hline
\end{tabular}

$* p<.05 . * * p<.01$

${ }^{\text {a }}$ Statistics outside the brackets concern the Personal Self-Care outcome variable

${ }^{\mathrm{b}}$ Statistics inside the brackets relate to the Professional Self-Care outcome variable

to previous research that has examined self-compassion, more broadly, within the helping professions (e.g., Duarte et al. 2016; Durkin et al. 2016).

Similarly, the mean personal self-care score was 59.71 $(\mathrm{SD}=8.53)$ and the professional self-care score was 82.52 $(\mathrm{SD}=10.17)$. As was true regarding self-compassion, the mean self-care score related to personal self-care indicates that participants engage in a moderate amount of self-care. While professional self-care scores were higher, these scores still indicate room for improvement. Again, these data for affirm some of the previous, albeit limited, research examining self-care among helping professionals. For instance, in a study that examined self-care among social workers, Bloomquist et al. (2015) concluded that participants in their sample engaged in self-care on a "limited basis" (p. 292). Miller et al. (2017) reached similar conclusions among a sample of social workers employed in healthcare settings.

Given the notion that both self-compassion and self-care may be impactful in assuaging the problematic employment circumstances plaguing social work clinicians, findings from the current study may mirror previous, and raise additional, concerns about the well-being of the clinical social workers. Indeed, these findings underscore that fostering selfcompassion and self-care are areas of needed improvement in clinical social work practice, education, and policy.

\section{Demographic and Professional Variables}

In terms of relationships among outcome variables, significant relationships were found between all three variables (except for self-compassion and hours worked per week). In summary, the older and more years in clinical social work practice, the more self-compassion, personal self-care, and professional self-care the participant engaged in. As well, the healthier one perceived themselves to be, the higher their self-compassion and self-care scores (please see Table 4).

These findings regarding age and experience may be related to professional and personal development. For instance, professionals who sustain themselves in the field may do so by developing these skills. Likewise, these 
findings may be indicative of retention in the profession and burnout. That is, obviously, people who have left the profession are not captured in this study. The younger and less experienced respondents with lower scores may be a precursor to burnout and leaving the profession. Concomitantly, the older and more experienced respondents may be representative of those who stay in the profession. Further still, individuals who lack self-compassion and/or self-care may tend to burnout and leave the profession before a certain age. No matter, this finding indicates the need for attention to self-care and self-compassion as strategies for retention in the profession.

Health status may be linked by the interactional nature of these phenomena. That is, as discussed earlier, self-care and self-compassion are linked with myriad health indicators. Also, this finding may be related to the more traditional understanding of self-care. Although a more holistic understanding of self-care is emerging, self-care is most commonly interpreted as "physical activities," such as going to the gym. Thus, respondents with poor physical health may see themselves with limited options related to self-care. This finding reinforces the need for a more holistic view of self-care.

Analyses also revealed several group differences for selfcompassion and self-care scores, respectively. For instance, data suggest that individuals who are part of a professional member organization, such as the National Association of Social Workers, had higher self-compassion, personal, and professional self-care scores, respectively. Similar findings held true for participants in supervisory roles and by financial status. Additionally, findings indicate that individuals who are married engaged in significantly more self-care practices than those who were not.

All told, these group differences may be related to, or connected with, the support, social and otherwise, associated with being in a professional organization and/or married/ partnered. Several authors (e.g., Durkin et al. 2016; Gerber et al. 2015) have linked self-compassion with the ability to develop and maintain positive, supportive relationships. Others (Cox and Steiner 2013; Orlinsky and Ronnestad 2005) have made similar assertions about self-care. Assuredly, the interaction between relationships, both personal and professional, and self-care and self-compassion, should be examined.

\section{Self-Compassion as a Predictor of Self-Care}

Findings from this study suggest that self-compassion is a significant predictor of self-care practices. Self-compassion was a unique, and was the strongest, predictor of personal and professional self-care, respectively. These findings are included in Table 5. These findings shed new light on the predictive relationship of self-compassion on self-care.
Whilst findings associated with the predictive relationship between self-compassion and self-care are new, these findings seem somewhat, at least theoretically, intuitive. As previously noted, self-compassion is the practice of creating and nurturing a relationship with the self that allows a sense of caring (Neff 2003b). Neff's description and related research on self-compassion points to this finding. That is, one might surmise that a person who is self-compassionate may also be inclined to engage in self-care practices. Data from the current study affirms this notion and informs practice implications.

\section{Limitations}

As with all research, this study is not without limitations. All participants self-selected into this study and all selfidentified as a social work clinician in one southeastern state. Given the paucity of literature related to self-care and self-compassion among clinical social workers, both respectively and in conjunction, this study was framed as exploratory research. The sample was overwhelmingly White and Female and may not reflect the broader clinical workforce. Adding additional perspectives, or a more diverse sample, geographically and otherwise, may have impacted findings related to this study. As well, while the self-compassion measure has been critically examined via previous research studies, the SCPS has been examined less so. Future research should look to address these limitations. Given these limitations, and others, generalization related to this study should be inferred carefully.

\section{Implications}

Several key implications can be derived from this study. The following discussion briefly outlines practice strategies; training and education; and, research implications associated with the afore-presented research findings.

\section{Practice}

As indicated, there is room for improvement in self-compassion and self-care, respectively. These facets of wellbeing are of paramount importance, given the contemporary practice landscape, and subsequent consequences, for many social work clinicians. As such, social work clinicians should be actively supported in fostering self-compassion, and engaging in self-care practices.

Interestingly, data from the current study suggest that fostering self-compassion may also increase self-care practices. Indeed, this study points to the potential for melding self-compassion and self-care. That is, both self-compassion and self-care, as professional practice skills, can be learned. 
In practice roles and settings, explicit attention to these complementary phenomena could have exponential impact. Pragmatically, individual practitioners can begin this process by assessing their levels of self-care and self-compassion. Then, they can engage in professional development to build these skills.

Organizations can support practitioners through providing professional development opportunities that focus on learning about how to practice self-care and deepen selfcompassion. These opportunities could be part of broadbased organizational wellness initiatives, which also address systemic factors. Also, supervision, even for seasoned professionals, can be an integral component in fostering selfcompassion and promoting self-care. Accountability is another important factor in this development. Teams can institute accountability groups that promote ongoing attention to self-care and self-compassion. As well, supervisors may even integrate aspects of self-care and self-compassion into ongoing employee evaluations and professional development plans. These steps would certainly convey importance related to these concepts and help to identify strategies to support employees in engaging in self-care and self-compassion.

As noted above, younger and less experienced respondents had lower self-care and self-compassion scores. In addition to the implications noted above regarding professional development and organizational support, this finding has implications for retention. That is, individual practitioners may benefit from explicit attention to self-care and selfcompassion in sustaining them in their professional roles. Organizations that invest in supporting their employees in these endeavors will benefit. Additionally, organizations may look to ways to more adeptly support and socialize newer employees via mentorship and peer support structures.

Likewise, the social work profession, itself, should consider the impact of self-care and self-compassion on sustaining a viable workforce. This may be particularly true in the realm of clinical social work. The finding that membership in a professional organization is predictive of self-care and self-compassion has pragmatic implications for these organizations. They could leverage this finding to promote membership benefits, while providing resources to practitioners and agencies to promote professional development in self-care and self-compassion. All of the above efforts have practical implications for sustaining the clinical social work workforce.

\section{Education and Training}

The attention to sustaining the workforce is directly related to education and training. Several authors have called for more attention to self-care during educational programs and ongoing training endeavors (Bonifas and Napoli 2014;
Smullens 2015; Moore et al. 2011). The current study suggests that fostering self-compassion may be one key strategy for improving self-care practice. Yet, there are few educational/training frameworks related to addressing selfcompassion among social work clinicians. Professional education increasingly focuses on the development of competencies. With growing evidence related to practice implications, competency frameworks on self-compassion, self-care, and their interactive nature is needed.

In addition, continuing education (e.g., CE units) about self-compassion and self-care is needed to reinforce and continue to inform the development of these aspects of ongoing professional practice. Studies suggest that brief trainings, with appropriate follow ups, can be an effective way to teach skills (e.g., Crane and Ward 2016). Experts in both self-care and self-compassion assert that these skills are not achieved through a single educational offering (e.g., Neff 2011). As with any essential skill, ongoing attention is necessary for deepening competency in self-care and self-compassion. In addition to CE offering, social work programs might look to implement credit-bearing self-care/self-compassion courses to students.

Professional organizations play a key role in this development. NASW (2008) asserted that self-care is a core element of ethical practice and explicated how the social work profession should promote attention to self-care. Professional organizations, agency administrators, policy-makers and other leaders in clinical social work can implement this assertion. These entities have particular roles in ensuring that the resources are available to support further development, including research efforts.

\section{Research}

As with any exploratory study, this study both garnered insights and refined critical questions for further exploration. The current study needs to be replicated, perhaps on a national level, which could take into account the limitations listed earlier. Also, the findings of this study need to be further tested through practice interventions, with accompanying evaluative measures. Explicitly, more study of the interactive nature and conceptual relationship between self-care and self-compassion is needed. Professional development approaches to teaching both self-care and self-compassion need to be developed and critically evaluated (e.g., pre/post methods, etc.), which also entails more critically assessing measures for self-care. Additionally, studies that examine organizational approaches to impact self-care and selfcompassion are warranted. Future studies can provide more insight about how to harness these interactive phenomena for exponential impact. 
Funding There is no funding to report for this study.

\section{Compliance with Ethical Standards}

Ethical Approval All procedures performed in studies involving human participants were in accordance with the ethical standards of the institutional and/or national research committee and with the 1964 Helsinki declaration and its later amendments or comparable ethical standards.

Informed Consent Informed consent was obtained from all individual participants included in the study.

\section{References}

Arrington, P. (2008). Stress at work: How do social workers cope? NASW Membership Workforce Study. Washington, DC: National Association of Social Workers.

Asuero, A. M., Queralto, J. M., Pujol-Ribera, E., Berenguera, A., Rodriguez-Blano, T., \& Epstein, R. M. (2014). Effectiveness of a mindfulness education program in primary health care professionals: A pragmatic controlled trial. Journal of Continuing Education in the Health Professions, 34(1), 4-12. https://doi.org/10.1002/ chp. 21211.

Ben-Porat, A., \& Itzhaky, H. (2009). Implications of treating family violence for the therapist: Secondary traumatization, vicarious traumatization, and growth. Journal of Family Violence, 24(7), 507-515. https://doi.org/10.1007/s10896-009-9249-0.

Berthold, S. M., \& Fischman, Y. (2014). Social work with trauma survivors: Collaboration with interpreters. Social Work, 59(2), 103-110. https://doi.org/10.1093/sw/swu011.

Bloomquist, K. R., Wood, L., Friedmeyer-Trainor, K., \& Kim, H. W. (2015). Self-care and professional quality of life: Predictive factors among msw practitioners. Advances in Social Work, 16(2), 292-311. https://doi.org/10.18060/18760.

Bonifas, R., \& Napoli, M. (2014). Mindfully Increasing Quality of Life: A Promising Curriculum for MSW Students. Social Work Education, 33(4), 469-484.

Bourassa, D. B. (2009). Compassion fatigue and the adult protective service worker. Journal of Gerontological Social Work, 52(3), 215-229. https://doi.org/10.1080/01634370802609296.

Bride, B. E., \& Figley, C. R. (2009). Secondary trauma and military veteran caregivers. Smith College Studies in Social Work, 79(3), 315-329. https://doi.org/10.1080/00377310903130357.

Bush, A. (2015). Simple self-care for therapists: Restorative practices to weave through your workday. New York, NY: W. W. Norton.

Christopher, J. C., \& Maris, J. A. (2010). Integrating mindfulness as self-care into counseling and psychotherapy training. Counseling and Psychotherapy Research, 10(2), 114-125. https://doi. org/10.1080/14733141003750285.

Cleantis, T. (2017). An invitation to self-care: Why learning to nurture yourself is the key to the life you've always wanted, 7 principles for abundant living. Center City, MN: Hazelden.

Coakes, S. J. (2005). SPSS: Analysis without Anguish: Version 12.0 for Windows. Milton: Wiley.

Cohen, M., \& Gagin, R. (2005). Can skill-development training alleviate burnout in hospital social workers? Social Work Health Care, 40(4), 83-97. https://doi.org/10.1300/J010v40n04_05.

Compassion [Def. 1]. (2017). In Merriam-Webster online. Retrieved October 20, 2018, from https://www.merriamwebster.com/ dictionary/compassion?utm_campaign=sd\&utm_mediu $\mathrm{m}=$ serp\&utm_source $=$ jsonld.
Cox, K., \& Steiner, S. (2013). Self-care in social work: A guide for practitioners, supervisors, and administrators. Washington, DC: NASW Press.

Crane, P. J., \& Ward, S. F. (2016). Self-healing and self-care for nurses. AORN Journal, 104(5), 386-400. https://doi.org/10.1016/j. aorn.2016.09.007.

Dorociak, K. E., Rupert, P. A., Bryant, F. B., \& Zahniser, E. (2017). Development of professional self-care scale. Journal of Counseling Psychology, 64(3), 325-334. https://doi.org/10.1037/cou00 00206.

Duarte, J., Pinto-Gouveia, J., \& Cruz, B. (2016). Relationships between nurses' empathy, self-compassion and dimensions of professional quality of life: A cross-sectional study. International Journal of Nursing Studies, 60, 1-11. https://doi.org/10.1016/j.ijnur stu.2016.02.015.

Dunkley, J., \& Whelan, T. (2006). Vicarious traumatization: Current status and future directions. British Journal of Guidance and Counselling, 34(1), 107-116.

Durkin, M., Beaumont, E., Hollins-Martin, C. J., \& Carson, J. (2016). A pilot study exploring the relationship between self-compassion, self-judgement, self-kindness, compassion, professional quality of life and wellbeing among UK community nurses. Nurses Education Today, 46, 109-114. https://doi.org/10.1016/j. nedt.2016.08.030.

Ferguson, L. J., Kowalski, K. C., Mack, D. E., \& Sabiston, C. M. (2014). Exploring self-compassion and eudaimonic well-being in young women athletes. Journal of Sport \& Exercise Psychology, 36(2), 203-216. https://doi.org/10.1123/jsep.2013-0096.

Gerber, Z., Tolmacz, R., \& Doron, Y. (2015). Self-compassion and forms of concern for others. Personality and Individual Differences, 86, 394-400. https://doi.org/10.1016/j.paid.2015.06.052.

Hair, J. F., Anderson, R. E., Tatham, R. L., \& Black, W. C. (1998). Multivariate data analysis (5th ed.). Upper Saddle River: PrenticeHall International Inc.

Kintzle, S., Yarvis, J. S., \& Bride, B. E. (2013). Secondary traumatic stress in military primary and mental health care providers. Military Medicine, 178(12), 1310-1315.

Lee, J. J., \& Miller, S. E. (2013). A self-care framework for social workers: Building a strong foundation for practice. Families in Society, 94(2), 96-103. https://doi.org/10.1606/1044-3894.4289.

Miller, J. J., Lianekhammy, J., Pope, N., Lee, J., \& Grise-Owens, E. (2017) Self-care among healthcare social workers: An exploratory study. Social Work in Health Care, 56(10), 865-883.

Moore, S. E., Bledsoe, L. K., Perry, A. R., \& Robinson, M. A. (2011). Social work students and self-care: A model assignment for teaching. Journal of Social Work Education, 47(3), 545-553. https:// doi.org/10.2307/23044470.

National Association of Social Workers. (2008). National Association of Social Workers membership workforce study: Overview of survey participants. Washington, DC: Author.

Neff, K. D. (2003a). The development and validation of a scale to measure self-compassion. Self and Identity, 2(3), 223-250.

Neff, K. D. (2003b). Self-compassion: An alternative conceptualization of a healthy attitude toward oneself. Self and Identity, 2, 85-102.

Neff, K. (2011). Self-compassion: The proven power of being kind to yourself. New York: HarperCollins.

Neff, K. D., \& Beretvas, S. N. (2013). The role of self-compassion in romantic relationships. Self and Identity, 12(1), 78-98. https://doi. org/10.1080/15298868.2011.639548.

Neff, K. D., \& Germer, C. K. (2013). A pilot study and randomized control trial of the mindful self-compassion program. Journal of Clinical Psychology, 69(1), 28-44. https://doi.org/10.1002/ jclp.21923.

Neff, K. D., \& Germer, C. K. (2017). Self-compassion and psychological wellbeing. In J. Doty (Ed.), Oxford handbook of compassion science (pp. 371-385). Oxford: Oxford University Press. 
Neff, K. D., Pisitsungkagarn, K., \& Hsieh, Y. P. (2008). Self-compassion and self-construal in the United States, Thailand, and Taiwan. Journal of Cross Cultural Psychology, 39(3), 267-285. https://doi. org/10.1177/0022022108314544.

Orlinsky, D. E., \& Ronnestad, M. H. (2005). How psychotherapists develop: A study of therapeutic work and professional growth. Washington, DC: American Psychological Association.

Raes, F., Pommier, E., Neff, K. D., \& Van Gucht, D. (2011). Construction and factorial validation of a short form of the self-compassion scale. Clinical Psychology \& Psychotherapy, 18, 250-255. https ://doi.org/10.1002/cpp.702.

Salloum, A., Kondrat, D. C., Johnco, C., \& Olsen, K. R. (2015). The role of self-care on compassion satisfaction, burnout, and secondary trauma among child welfare workers. Children and Youth Services Review, 49, 54-61. https://doi.org/10.1016/j.childyouth .2014.12.023.

Sanso, N., Galiana, L., Oliver, A., Pascual, A., Sinclair, S., \& Benito, E. (2015). Palliative care professionals' inner life: Exploring the relationships among awareness, self-care and compassion satisfaction and fatigue, burn out, and coping with death. Journal of Pain and Symptom Management, 50(2), 200-207. https://doi.org/10.1016/j. jpainsymman.2015.02.013.

Sirois, F. M., Kitner, R., \& Hirsch, J. K. (2015). Self-compassion, affect, and health promoting behaviors. Health Psychology, 34(6), 661-669. https://doi.org/10.1037/hea0000158.

Smullens, S. (2015). Burnout and self-care in social work: A guidebook for students and those in mental health and related professions. Washington, DC: NASW Press.

Ting, L., Jacobson, J. M., Sanders, S., Bride, B. E., \& Harrington, D. (2005). The secondary traumatic stress scale (STSS): Confirmatory factor analyses with a national sample of mental health social workers. Journal of Human Behavior in the Social Environment, 11(3-4), 177-194. https://doi.org/10.1300/J137v11n03_09.

Van Dam, N. T., Sheppard, S. C., Forsyth, J. P., \& Earleywine, M. (2011). Self compassion is a better predictor than mindfulness of symptom severity and quality of life in mixed anxiety and depression. Journal of Anxiety Disorders, 25, 123-130. https:// doi.org/10.1016/j.janxdis.2010.08.011.

Whitaker, T., Weismiller, T., \& Clark, E. (2006). Assuring the sufficiency of a frontline workforce: A national study of licensed social workers. Executive summary. Washington, DC: National Association of Social Workers.

Yarnell, L. M., Stafford, R. E., Neff, K. D., Reilly, E. D., Knox, M. C., \& Mullarkey, M. (2015). Meta-analysis of gender differences in self-compassion. Self and Identity, 14(5), 499-520. https://doi. org/10.1080/15298868.2015.1029966.

Publisher's Note Springer Nature remains neutral with regard to jurisdictional claims in published maps and institutional affiliations.

J. Jay Miller Ph.D. is the Associate Dean for Research, Associate Professor, and Director of the Self-Care Lab at the University of Kentucky College of Social Work.

Jacquelyn Lee is an Associate Professor at the University of North Carolina, Wilmington.

Chunling Niu is the Research Administrator at the Self-Care Lab at the University of Kentucky.

Erlene Grise-Owens is the Principal Partner at The Wellness Group, ETC.

Molly Bode is a Research Assistant at the Self-Care Lab at the University of Kentucky. 